\title{
BMJ Open The relationship between school type and academic performance at medical school: a national, multi-cohort study
}

\author{
Ben Kumwenda, ${ }^{1}$ Jennifer A Cleland, ${ }^{1}$ Kim Walker, ${ }^{2}$ Amanda J Lee, ${ }^{3}$ \\ Rachel Greatrix ${ }^{4}$
}

To cite: Kumwenda $B$, Cleland JA, Walker K, et al. The relationship between school type and academic performance at medical school: a national, multi-cohort study. BMJ Open 2017;7:e016291. doi:10.1136/ bmjopen-2017-016291

- Prepublication history and additional material for this paper are available online. To view these files please visit the journal online (http://dx.doi. org/10.1136/bmjopen-2017016291).

Received 5 February 2017

Revised 4 July 2017

Accepted 12 July 2017

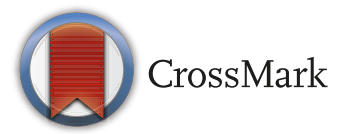

1 Institute of Education for Medical and Dental Sciences, School of Medicine, Medical Sciences \& Nutrition, University of Aberdeen, Aberdeen, UK ${ }^{2}$ NHS Education for Scotland and UK Foundation Programme, Aberdeen, UK

${ }^{3}$ Medical Statistics Team, School of Medicine, Medical Sciences \& Nutrition, University of Aberdeen, Aberdeen, UK

${ }^{4}$ UK Clinical Aptitude Test (UKCAT) Foundation, University of Nottingham, Nottingham, UK

Correspondence to

Ben Kumwenda;

r01bk15@abdn.ac.uk

\section{ABSTRACT}

Objectives Differential attainment in school examinations is one of the barriers to increasing student diversity in medicine. However, studies on the predictive validity of prior academic achievement and educational performance at medical school are contradictory, possibly due to singlesite studies or studies which focus only on early years' performance. To address these gaps, we examined the relationship between sociodemographic factors, including school type and average educational performance throughout medical school across a large number of diverse medical programmes.

Methods This retrospective study analysed data from students who graduated from 33 UK medical schools between 2012 and 2013. We included candidates' demographics, pre-entry grades (adjusted Universities and Colleges Admissions Service tariff scores) preadmission test scores (UK Clinical Aptitude Test (UKCAT) and Graduate Medical School Admissions Test (GAMSAT)) and used the UK Foundation Programme's educational performance measure (EPM) decile as an outcome measure. Logistic regression was used to assess the independent relationship between students' background characteristics and EPM ranking.

Results Students from independent schools had significantly higher mean UKCAT scores (2535.1, $\mathrm{SD}=209.6$ ) than students from state-funded schools (2506.1, SD=224.0, $p<0.001)$. Similarly, students from independent schools came into medical school with significantly higher mean GAMSAT scores $(63.9, \mathrm{SD}=6.9)$ than students from state-funded schools $(60.8, S D=7.1$, $\mathrm{p}<0.001)$. However, students from state-funded schools were almost twice as likely $(\mathrm{OR}=2.01,95 \% \mathrm{Cl} 1.49$ to 2.73) to finish in the highest rank of the EPM ranking than those who attended independent schools.

Conclusions This is the first large-scale study to examine directly the relationship between school type and overall performance at medical school. Our findings provide modest supportive evidence that, when students from independent and state schools enter with similar pre-entry grades, once in medical school, students from state-funded schools are likely to outperform students from independent schools. This evidence contributes to discussions around contextualising medical admission.

\section{INTRODUCTION}

The medical profession has long been socially exclusive and dominated by those from

\section{Strengths and limitations of this study}

- This is the first UK multi-site study to examine the relationship between prior attainment, (high) school type and performance throughout medical school.

- The strength of this study resides in our ability to longitudinally track the influence of a basket of contextual indicators and demonstrate how these predict success at medical school.

- We acknowledge the potential limitation of dichotomising schools by funding source because of the overlap of some schools that are statefunded but share the academic characteristics of independent schools.

- Measures of disadvantage such as neighbourhood location (POLAR) or National Statistics SocioEconomic Status Classification and self-declared parental occupation are known to have weaknesses.

- The study only looked at students who were admitted and completed their medical degree. Students who failed or dropped out were excluded from the analysis.

relatively affluent backgrounds. While the demand for access to the profession remains high, this unbalanced pattern is largely associated with the differences in entry level attainment. For example, students from disadvantaged backgrounds are reportedly more likely to obtain lower school grades than students from more affluent backgrounds. ${ }^{1-3}$ However, the issue of social origins and access to the professions is more complex than the differences in prior academic attainment alone. ${ }^{45}$ Across the world, those with the attributes to successfully study medicine and be doctors face disadvantages associated with sociodemographic factors such as ethnicity, minority group membership and/or low income. ${ }^{6-11}$

In the UK, evidence suggests that the medical student body has become increasingly diverse when it comes to gender, ethnicity and age. That progress, however, has not been mirrored by a similar change 
in the socioeconomic background of medical students. ${ }^{12}$ The reasons for this are hugely complex, tied up with wider societal issues of social justice and social equality. ${ }^{13}$ However, it is clear that, in a medical school selection system where the first hurdle is prior academic achievement, differences in participation are associated with a gap in educational attainment between students from socioeconomically privileged backgrounds and those from more disadvantaged groups. ${ }^{10}{ }^{14}$ This is linked to the type of schools attended. Only $7 \%$ of the UK population goes to independent schools, yet across the years, a pattern of more than $20 \%$ of medical students coming from such schools has remained static, ${ }^{15}$ at least in part because students in independent schools do better on school leaving examinations. ${ }^{1016-18}$

But, are stronger pre-entry grades an indicator of potential at medical school? The wider literature is conflicting. Earlier studies which pre-dated changes in UK school qualifications indicated that school leaving examination results do predict academic performance at medical school, at least to some extent. ${ }^{19-21}$ More recent studies have looked at the interaction between school type and prior academic performance and performance on medical school assessments. In a study of 12 UK medical schools, McManus and colleagues found that, ${ }^{22}$ after adjusting for students' individual educational attainment, students educated at selective (mostly independent) schools performed less well on year one medical school assessments than those educated in non-selective (mostly state-funded) schools. On the other hand, Thiele $e t a l^{23}$ in a single-site study, found that most of the attainment differences observed between students from different types of school either decreased or disappeared by year four of a 5-year programme.

These contradictory results are of interest. In singlesite studies, it may be that the differences are due the outcome measures used, rather than the influence of school per se. Since McManus et al's study looked at year one outcomes only, it may be that school-related differences are evened out the longer one is at medical school. The latter suggestion is supported by the wider UK literature. For example, Higher Education Funding Council for England (HEFCE) ${ }^{24} 25$ studied the achievement of a full cohort of entrants with A-level qualifications to degree courses in England in 1997-1998 and 2007-2008, respectively. They reported that, at all levels of prior attainment, state-schooled students typically outperformed otherwise comparable independent school students in terms of their university degree outcomes. ${ }^{24} 25$ The HEFCE 2014 report found that this difference was still statistically significant when A-level attainment was very high and at institutions with high entry tariffs, but did not include medicine in their analysis, presumably because medical schools do not use traditional degree classifications.

Our aim was to address this gap in the literature by evaluating the predictive validity of a range of sociodemographic factors, including school type, in relation to academic performance throughout medical school.
Our study is timely, given there is increasing discussion around the use of 'contextual data' or 'contextual admission' (CA) in UK medical education. This refers to taking into account the context and circumstances in which applicants attain prior qualifications when assessing their potential to do well at medical school, given the association between systemic and social factors and attainment. ${ }^{26-28}$ A recent review of the literature, commissioned by the Medical Schools Council of the UK, but unpublished as yet, highlighted a lack of direct evidence for the utility of commonly proposed CA markers but proposed that school type and/or school performance indicators may be useful CA markers, given the wider literature. ${ }^{29}$ Directly scrutinising the relationship between school type and total medical school performance will add significantly to this ongoing discussion.

\section{METHODS}

\section{Study population}

Our sample included students who graduated from 33 UK medical programmes in 2012 and 2013 who sat pre-entry tests (see later) in 2006, 2007 or 2008 and, in their final year of study, applied for allocation into the stage of medical training which immediately follows medical school, the Foundation Programme. The sample included diverse medical programmes from across the UK, from older, more traditionally elite medical schools to newer schools established in the last 25 years. Traditional 5-year medical programmes were represented, as were accelerated 4-year graduate entry ones and extended 6-year programmes (representing programmes with preclinical years or an additional year of research). The programmes had different selection processes, but all used prior attainment as the first stage in the admissions process. ${ }^{30}$

The UK Medical Education Database (UKMED: https://www.ukmed.ac.uk/) provided participant socioeconomic, medical school admission and performance data and outcomes on the Foundation Programme allocation process which is managed by the United Kingdom Foundation Programme Office (UKFPO) (see later for further detail). Access to the data was only made available to members of the research team, and this was via a safe haven (to ensure adherence to the highest standards of security, governance and confidentiality when storing, handling and analysing identifiable data). Ethics approval was not required because the focus of this study was a secondary analysis of anonymised data.

\section{DATA DESCRIPTION}

\section{Sociodemographic data}

We focused on those who were UK-domiciled on application to medical school only as selection of demographic factors was guided by previous UK research on widening participation. ${ }^{27}$ 31-33 The following indicators were used to categorise students as educationally disadvantaged or 
not: parental occupation (derived from National Statistics Socioeconomic Classification); free school meals; income support; POLAR (which is an indicator of the participation of young people in higher education by geographic area) and parental education. Data on age, gender, ethnicity and whether the individual was a school leaver or a graduate at the time of entry to medical school were also included.

For purposes of this study, the type of school attended was defined according to funding criteria, whether statefunded or privately funded. Here in the UK, state-funded education is free and mostly non-selective, while privately funded schools are selective, they require pupils to pay tuition fees and have a greater proportion of pupils from affluent backgrounds. For this reason, we have classified privately funded schools as independent. We acknowledge the potential limitation of dichotomising schools by funding source as there is an overlap of some schools, for example grammar schools in England, which are both state-funded and selective. Such schools may even share the academic characteristics of independent schools ${ }^{22}$ but this categorisation was deemed appropriate for the analysis because it is a commonly used contextual factor in admissions practice and thus has potential implications for admissions policy.

The dominant ethnic category was White, and this was compared against Black, Asian and Mixed ethnic groups. The age at entry to medical school was dichotomised to typical school leavers (aged 17-20 years) and mature students (aged 21 and above). Students were also categorised as graduates (or not) at the time they went to medical school. Demographic information was also available for the country of domicile and type of course attended.

\section{Outcome data}

The following pre-entry scores were used in the initial analysis: Universities and Colleges Admissions Service (UCAS) tariff points (a means of differentiating students' grades obtained at the end of High School education) and performance on the UK Clinical Aptitude Test (UKCAT) or Graduate Medical School Admissions Test (GAMSAT). Since our focus was on the graduating cohort, the pre-entry test scores are not presented in a conventional cohort approach. For example, not all students who graduated in 2013 sat the UKCAT or GAMSAT in 2008. Some may have taken an earlier (or later) exam, depending on the degree programme they had enrolled, while others could have repeated a year. To control for the school performance effect, ${ }^{25}$ we capped the UCAS tariff points into an average point score per A-level student (relative to the average for their school in the exam year).

All medical students studying in the UK who wish to enter the UKFPO obtain two indicators of performance: an educational performance measure (EPM) and the equated score they achieve for a bespoke situational judgement test (http://www.foundationprogramme. nhs.uk/pages/medical-students/SJT-EPM). ${ }^{34}{ }^{35}$ The
EPM is a decile ranking (within each school) of an individual student's academic performance across all years of medical school except the final year, plus additional points for an additional degree and up to two publications. These have a combined score of a maximum of 50 points. Our interest in this paper was the performance on medical school assessments, so we looked only at EPM decile, not these plus additional points.

EPM data were ranked differently across the two cohorts. In 2012, graduating students were competition-ranked into quartiles within individual medical schools (cut-points awarded scores of 34, 36, 38 and 40). The EPM ranking for 2013 cohort was in deciles. The first decile received a score of 43 , those in the second decile received a score of 42 and so on until students in the 10th or lowest decile were awarded a score of 34 . Only ranked data were available via UKMED, so we compared the top $20 \%$ versus the lowest $20 \%$ in 2013 with top versus bottom quartile in 2012.

\section{Statistical analysis}

All data were analysed using IBM SPSS V.23.0 and STATA. First, we looked at the relationship between demographic factors and pre-entry scores (UCAS Tariff, UKCAT and GAMSAT) to establish if our sample was a true reflection of the medical school population. These continuous factor scores were normally distributed, so we used independent samples t-tests and one-way analysis of variance (ANOVA) to compare across independent groups.

Mixed-effects binary logistic regression models were constructed to assess the independent relationship between the demographic factors and the EPM rankings. We coded the EPM variables to a binary variable to allow us to analyse the odds of a student finishing in the highest ranking, against those finishing in the lowest ranking of the year group. The decision to reduce the EPM differences into a simple binary code was guided by a sampling procedure known as Extreme Groups Approach (EGA). ${ }^{36} 37$ This procedure allows the extreme groups, which can be chosen on the basis of sample dependent quintiles or cut-off points, to be analysed in terms of low versus high. Thus, for the EPM of 2012, we created a binary variable that compared the highest quartile versus the lowest quartile. Similarly, for the 2013 EPM, we created a binary variable that compared students in the top quintile against those in the bottom quintile. Univariate analysis was used as a preliminary step to guide which predictor factors were to be considered for entry into the regression model. Statistical significance of associations between independent and outcome variables was assessed using the chi-square test. All variables with non-significant results (using a conservative $\mathrm{p}<0.1$ to not miss any borderline significant predictors) were then dropped from inclusion into the multivariable logistic model.

We used the forward conditional selection to create the base model and examined collinearity to prevent two highly correlated factors entering the model together. Significant $(p \leq 0.05)$ covariates were added at each stage 
of the analysis until a model of best fit was identified. To optimise the model fit and to ensure inclusion of all individuals with non-missing values for the selected variables, the model was refitted using only those predictor variables that were significantly associated with EPM ranking in the base model. The data were transferred into STATA to fit a mixed-effects logistic regression model with a random intercept for medical school. This helped to control for the clustering effect of individual students within medical schools. Lastly, to ensure that patterns found with the highest and lowest EPM quantiles were consistent with those found when all EPM rankings were included, we re-fitted the models with all the EPM quartiles (2012) and EMP quintile (2013) scores treated as ordinal categorical outcomes. Detailed results of mixed-effect ordinal logistic regression are available as an online supplementary table

\section{RESULTS}

Tables 1 and 2 present a detailed breakdown of the sample in terms of sociodemographic characteristics and the outcome variables. The valid sample sizes and percentages in these tables vary due to varying degrees of missing data. Table 1 gives a summary of students' pre-entry performance (UCAS tariff points, UKCAT and GAMSAT). Students from state-funded schools had significantly lower adjusted UCAS tariff points (508.3, $\mathrm{SD}=104.22)$ than students from independent schools (575.29, $\mathrm{SD}=83.82, \mathrm{p}<0.001)$. Significant differences were also observed in the UKCAT scores where students from independent schools had higher mean scores (2535.1, $\mathrm{SD}=209.6)$ than students from state-funded schools (2506.1, $\mathrm{SD}=224.0, \mathrm{p}<0.001)$. Significant differences were also observed in GAMSAT scores where students from independent schools had higher mean scores (63.9, $\mathrm{SD}=7.0)$ than students from state-funded schools $(60.8$, $\mathrm{SD}=7.1, \mathrm{p}<0.001)$. There was a gap in the mean UKCAT score of nearly 40 points between students whose parental occupation was in the lowest socioeconomic group and students with parents in the professional occupations. Students who, at one time, were recipients of free school meals or income support also had lower UCAS tariff and UKCAT scores than their counterparts.

Table 2 reports a summary of the sociodemographic characteristics of the sample in relation to academic performance at medical school. Note that due to small numbers of those in lower socioeconomic classes (as noted in Parental National Statistics Socio-Economic Status Classification (NSSEC)), we do not report on students from NSSEC II-V separately. Rather, we collapsed NSSEC II, III, IV and V and compared it with NSSEC I -Managerial and professional occupations. In 2012, the following groups were significantly more likely to be represented in the top EPM quartile: females, graduates, mature students, those educated at a state-funded school, those with managerial/professional parents and those of white ethnicity. In 2013, the following groups were significantly more likely to be represented in the top two EPM deciles: females, non-graduates, school-leavers, those educated at a state school, those with managerial/ professional parents and those of white ethnicity. Finally, those in receipt of free school meals were significantly less likely to perform in the top quartile (2012) or top decile (2013). Those from families in receipt of income support were significantly less likely to be represented in the top decile in 2013, but this pattern was not apparent in the 2012 quartile data.

A mixed-effects binary logistic regression analysis was employed to predict the probability of graduating students finishing in the top tier of the EPM using those sociodemographic factors that were significant at the $\mathrm{p}<0.10$ level on univariate analysis. Table 3 illustrates that for the 2012 graduating cohort, gender, age, school type and ethnicity were significant predictors of EPM. After adjusting for other variables in the model, female students were more than twice as likely (OR=2.4, 95\% CI 1.88 to 3.13) to finish in the top $25 \%$ of the EPM than male students. Mature students were also more than twice as likely $(\mathrm{OR}=2.2$, $95 \%$ CI 1.66 to 3.10 ) to finish in the highest EPM quartile. Comparatively, students who attended state-funded schools were twice as likely ( $\mathrm{OR}=2.0,95 \%$ CI 1.49 to 2.73 ) to finish in the top $25 \%$ than students who attended privately funded schools.

The overall association between ethnicity and EPM remained highly significant. After multiple adjustment, students from Asian, Black, Mixed, and Other ethnic groups were less likely $(\mathrm{OR}=0.17,95 \% \mathrm{CI} 0.12$ to 0.24 ; $\mathrm{OR}=0.08,95 \%$ CI 0.02 to $0.24 ; \mathrm{OR}=0.45,95 \%$ CI 0.25 to 0.80 and $\mathrm{OR}=0.17,95 \% \mathrm{CI} 0.06$ to 0.53 , respectively) to finish in the top $25 \%$ than students from the majority white ethnic group. Note that socioeconomic status and course type were not significant independent predictors of EPM ranking after adjustment for other variables.

We then looked at the EPM for 2013 cohort which was presented differently from the previous year. Table 3 illustrates that gender, school type, ethnicity, country and programme type were significant predictors of outcome. Female students were nearly twice ( $\mathrm{OR}=1.80$, 95\% CI 1.54 to 2.11 ) as likely to finish in the top $20 \%$ of the group than male students. There was some consistency regarding students from the state-funded schools in that students from this cohort were 1.36 times (95\% CI 1.14 to 1.64 ) as more likely than independently schooled students to finish in the top $20 \%$ of the EPM. Similarly, differences in ethnic subgroups were also noted, with students coming from Asian, Black, Mixed and Other ethnic groups being less likely, than the majority white ethnic subgroup, to finish in the top $20 \%$ of the year group ( $\mathrm{OR}=0.21,95 \% \mathrm{CI}$ 0.17 to $0.26 ; \mathrm{OR}=0.11,95 \%$ CI 0.07 to $0.20 ; \mathrm{OR}=0.37$, $95 \%$ CI 0.25 to 0.55 and $\mathrm{OR}=0.30,95 \%$ CI 0.18 to 0.48 , respectively).

The mixed-effects ordinal logistic regression for EPM quartiles in 2012 confirmed the results above with odds of being in a higher quartile being 1.6 times higher for female students, 1.7 times higher for mature students 


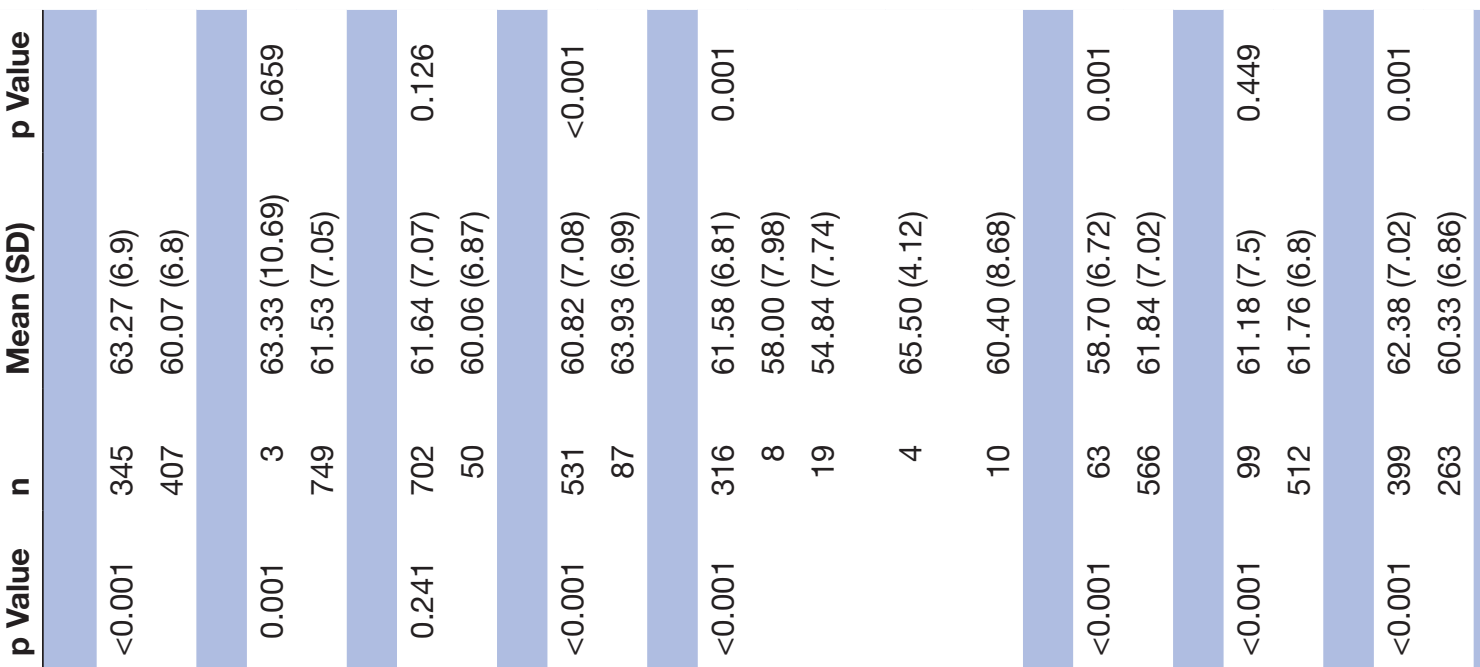

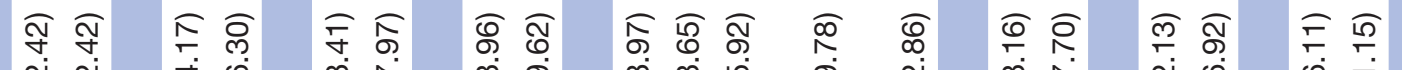

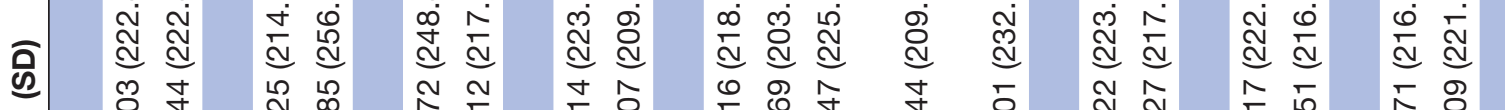
元

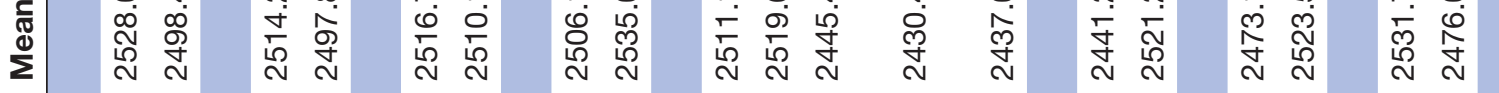

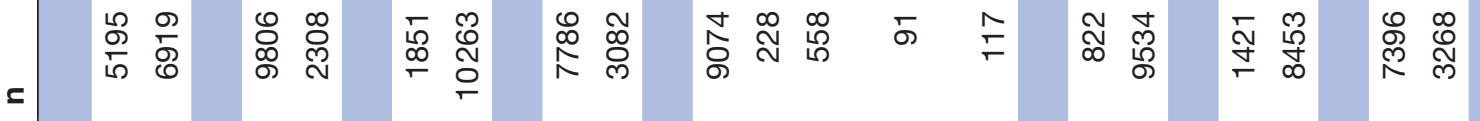

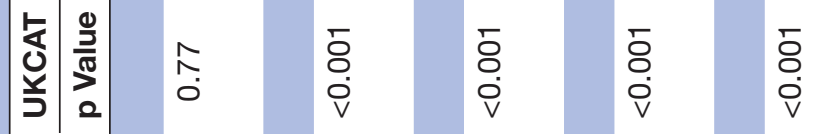

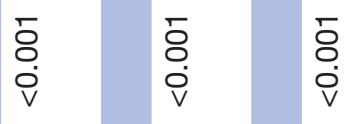

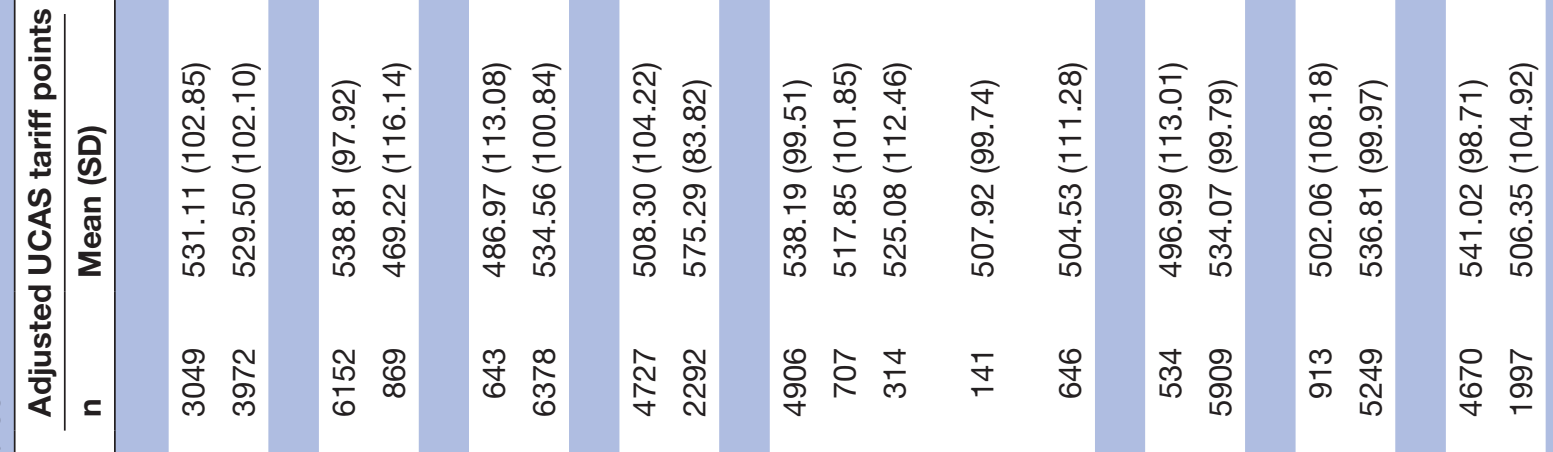




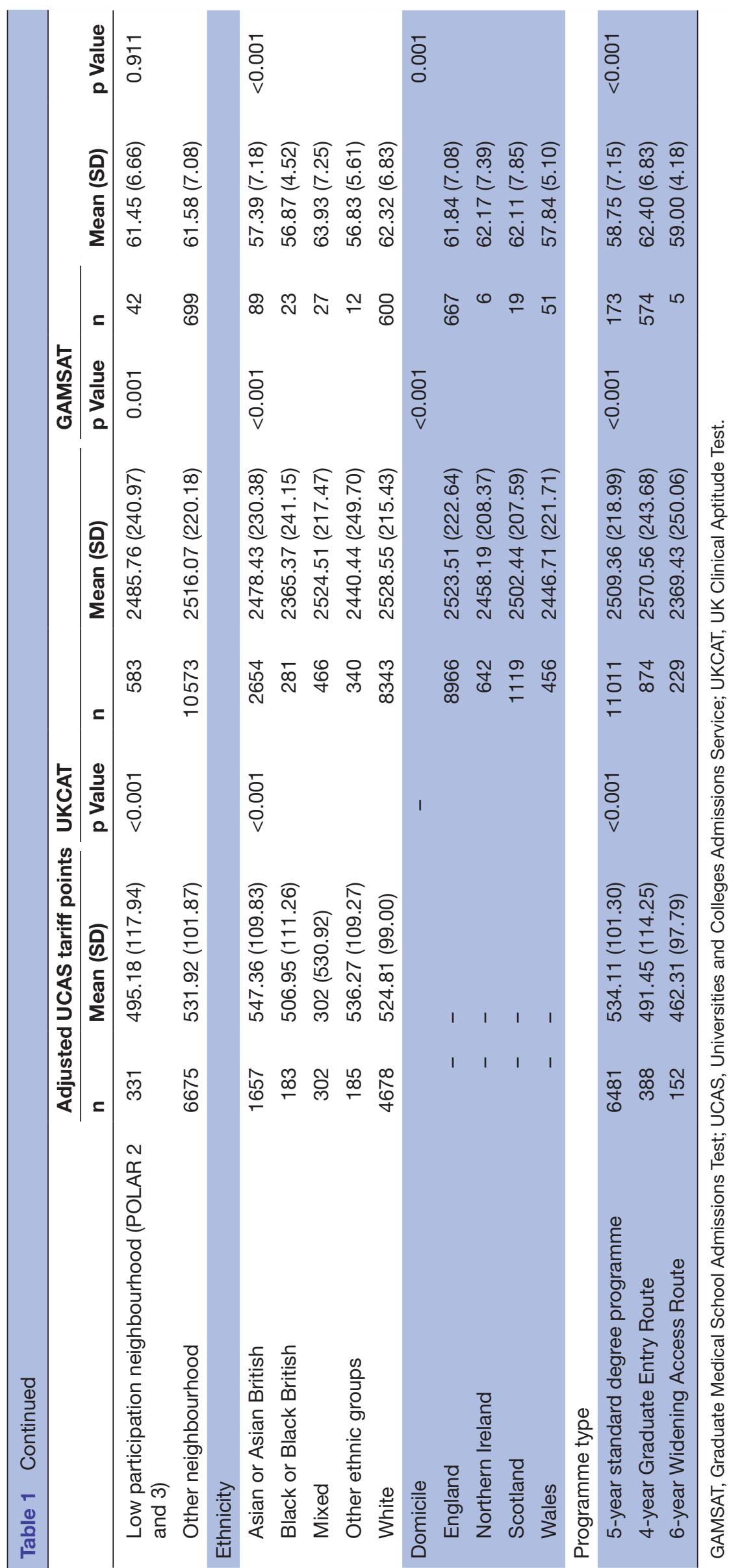


Table 2 Summary of performance at medical school

\begin{tabular}{|c|c|c|c|c|c|c|c|c|}
\hline \multirow[b]{3}{*}{ Total } & \multicolumn{4}{|c|}{ EPM 2012} & \multicolumn{4}{|c|}{ EPM 2013} \\
\hline & \multirow[b]{2}{*}{ Total } & \multirow[t]{2}{*}{$\begin{array}{l}\text { Bottom } \\
25 \%\end{array}$} & \multirow{2}{*}{$\begin{array}{l}\text { Top 25\% } \\
\text { n (\%) }\end{array}$} & \multirow[b]{2}{*}{$p$ Value } & \multirow[b]{2}{*}{ Total } & \multirow{2}{*}{$\begin{array}{l}\text { Bottom } \\
20 \% \\
\text { n (\%) } \\
\end{array}$} & \multirow{2}{*}{$\begin{array}{l}\text { Top 20\% } \\
\text { n (\%) }\end{array}$} & \multirow{2}{*}{$\begin{array}{l}p \text { Value } \\
n(\%)\end{array}$} \\
\hline & & & & & & & & \\
\hline Overall sample distribution & 1682 & $761(45.2)$ & $921(54.8)$ & N/A & 3213 & $1427(44.4)$ & $1786(55.6)$ & N/A \\
\hline \multicolumn{9}{|l|}{ Gender } \\
\hline Male & 662 & $370(55.9)$ & $292(44.1)$ & $<0.001$ & 1443 & $757(52.5)$ & $686(47.5)$ & $<0.001$ \\
\hline Female & 1020 & 391 (38.3) & $629(61.7)$ & & 1770 & $670(37.9)$ & $1100(62.1)$ & \\
\hline \multicolumn{9}{|l|}{ Age category } \\
\hline School leaver (17-20) & 1054 & $552(52.4)$ & $502(47.6)$ & $<0.001$ & 2825 & $1224(43.3)$ & $1601(56.7)$ & 0.001 \\
\hline Mature (21 above) & 628 & 209 (33.3) & $419(66.7)$ & & 388 & $203(52.3)$ & $185(47.7)$ & \\
\hline \multicolumn{9}{|l|}{ Highest qualification on entry } \\
\hline Graduate & 532 & $167(31.4)$ & $365(68.6)$ & $<0.001$ & 266 & $130(48.9)$ & $136(51.1)$ & 0.072 \\
\hline Non-Grad & 1150 & $594(51.7)$ & $556(48.3)$ & & 2947 & $1297(44.0)$ & $1650(56.0)$ & \\
\hline \multicolumn{9}{|l|}{ Type of secondary school attended } \\
\hline State-funded school or college & 1085 & $430(39.6)$ & $655(60.4)$ & $<0.001$ & 2175 & $933(42.9)$ & $1242(57.1)$ & 0.016 \\
\hline Independent school & 311 & $191(61.4)$ & $120(38.6)$ & & 944 & $445(47.1)$ & $499(52.9)$ & \\
\hline \multicolumn{9}{|l|}{ Parental NSSEC } \\
\hline $\begin{array}{l}\text { I-Managerial and professional } \\
\text { occupations }\end{array}$ & 1012 & $438(43.3)$ & $574(56.7)$ & 0.108 & 2257 & $939(41.6)$ & $1318(58.4)$ & 0.017 \\
\hline Other occupations (II-IV) & 93 & $47(50.5)$ & $46(49.5)$ & & 272 & $132(48.5)$ & $140(51.5)$ & \\
\hline \multicolumn{9}{|l|}{ Free school meal } \\
\hline Yes & 120 & $65(54.2)$ & $55(45.8)$ & 0.009 & 244 & $137(56.1)$ & $107(43.9)$ & $<0.001$ \\
\hline No & 1261 & $536(42.5)$ & $725(57.5)$ & & 2656 & $1107(41.7)$ & 1549 (58.3) & \\
\hline \multicolumn{9}{|l|}{ Income support } \\
\hline Yes & 204 & $100(49.0)$ & $104(51.0)$ & 0.053 & 419 & $210(50.1)$ & 209 (49.9) & $<0.001$ \\
\hline No & 1105 & $471(42.6)$ & $634(57.4)$ & & 2331 & $962(41.3)$ & $1369(58.7)$ & \\
\hline \multicolumn{9}{|l|}{ Parent education } \\
\hline University-educated parent & 925 & $408(44.1)$ & $517(55.9)$ & 0.309 & 2143 & $882(41.2)$ & $1261(58.8)$ & $<0.001$ \\
\hline No parent with a university degree & 491 & $209(42.6)$ & $282(57.4)$ & & 861 & $422(49.0)$ & $439(51.0)$ & \\
\hline \multicolumn{9}{|l|}{ POLAR (2 and 3) } \\
\hline Low participation neighbourhood & 91 & $38(41.8)$ & $53(58.2)$ & 0.383 & 171 & $83(48.5)$ & $88(51.5)$ & 0.149 \\
\hline Other neighbourhood & 1383 & $608(44.0)$ & $775(56.0)$ & & 3034 & $1340(44.2)$ & $1694(55.8)$ & \\
\hline \multicolumn{9}{|l|}{ Ethnic group } \\
\hline Asian or Asian British & 339 & $243(71.7)$ & $96(28.3)$ & $<0.001$ & 678 & $468(69.0)$ & $210(31.0)$ & $<0.001$ \\
\hline Black or Black British & 40 & $34(85.0)$ & $6(15.0)$ & & 99 & $76(76.8)$ & $23(23.2)$ & \\
\hline Mixed & 72 & $35(48.6)$ & $37(51.4)$ & & 121 & $68(56.2)$ & $53(43.8)$ & \\
\hline Other ethnic groups & 38 & $30(78.9)$ & $8(21.1)$ & & 77 & $47(61.0)$ & $30(39.0)$ & \\
\hline White & 1186 & $414(34.9)$ & $772(65.1)$ & & 2227 & $761(34.2)$ & $1466(65.8)$ & \\
\hline
\end{tabular}

EPM, educational performance measure; NSSEC, National Statistics Socio-Economic Status Classification.

and 1.3 times higher for state-funded students. When considering all quartiles, there was still significantly lower odds of being in a higher quartile for Asian, Black and Other ethnic groups than for White students, but the differences in odds were much less pronounced than when considering only the top and bottom quartiles. The mixed-effects ordinal logistic regression for EPM quintiles in 2013-2014 was fitted without including programme type as the small counts of graduate applicants prevented the model from converging. Otherwise earlier findings were confirmed with the odds of being in a higher quantile being 1.4 times higher for female students and 1.1 times higher for state-funded student. Non-white students had lower odds of being in a high quintile and those from 
Table 3 Mixed effect binary logistic regression between performance at medical school (highest and lowest quantiles) and sociodemographic variables

\begin{tabular}{|c|c|c|c|c|c|c|}
\hline \multirow{3}{*}{$\begin{array}{l}\text { Variables in the model } \\
\text { Fixed effects }\end{array}$} & \multicolumn{3}{|c|}{2012 EPM } & \multicolumn{3}{|c|}{2013 EPM } \\
\hline & \multirow{2}{*}{$\begin{array}{l}\text { OR } \\
\text { Lower }\end{array}$} & \multicolumn{2}{|c|}{$95 \% \mathrm{Cl}$ for OR } & \multirow{2}{*}{$\begin{array}{l}\text { OR } \\
\text { Upper }\end{array}$} & \multicolumn{2}{|c|}{$95 \% \mathrm{Cl}$ for OR } \\
\hline & & Upper & Lower & & & \\
\hline Female & 2.43 & 1.88 & 3.13 & 1.80 & 1.54 & 2.11 \\
\hline Mature (21+) & 2.27 & 1.66 & 3.10 & & & \\
\hline State-funded & 2.01 & 1.49 & 2.73 & 1.36 & 1.14 & 1.62 \\
\hline Asian & 0.17 & 0.12 & 0.24 & 0.21 & 0.17 & 0.26 \\
\hline Black & 0.08 & 0.02 & 0.24 & 0.11 & 0.07 & 0.20 \\
\hline Mixed & 0.45 & 0.25 & 0.80 & 0.37 & 0.25 & 0.55 \\
\hline Other ethnic groups & 0.17 & 0.06 & 0.53 & 0.30 & 0.18 & 0.48 \\
\hline Northern Ireland & & & & 0.29 & 0.19 & 0.44 \\
\hline Wales & & & & 0.68 & 0.45 & 1.02 \\
\hline Scotland & & & & 0.95 & 0.68 & 1.33 \\
\hline 4-year Grad Entry & & & & 0.08 & 0.02 & 0.28 \\
\hline $\begin{array}{l}\text { 6-year Widening Access } \\
\text { Route }\end{array}$ & & & & 0.39 & 0.22 & 0.67 \\
\hline Constant & 0.21 & 0.12 & 0.35 & 1.32 & 1.07 & 1.64 \\
\hline \multicolumn{7}{|l|}{ Random intercept } \\
\hline $\begin{array}{l}\text { Medical school } \\
\text { (variance) }\end{array}$ & 0.22 & 0.09 & 0.53 & 0.10 & 0.04 & 0.21 \\
\hline
\end{tabular}

EPM, educational performance measure.

Northern Ireland and Wales also had reduced odds. Full results of the mixed-effects ordinal logistic regression are presented in online supplementary table 1 and 2.

\section{DISCUSSION}

This is the first study which examines the relationship between prior attainment (as measured by UCAS Tariff), (high) school type and performance throughout medical school, as measured by the EPM (quartile/decile) which is used in the allocation process for the next stage of UK medical training, the Foundation Programme. Additionally, we examined these relationships across a large number of medical programmes from a range of diverse medical schools. We found that students from statefunded schools-where the majority of students from less advantaged backgrounds attend-entered medical school with similar prior attainment but significantly weaker outcomes on entry tests (UKCAT and GAMSAT) than entrants who attended independent schools. Yet, they were significantly more likely to finish in the highest tier of the EPM ranking than those students who attended independent schools. These findings indicate that, as students progress through medical school, any effect of schooling gradually declines, as has been noted in other UK degree programmes. ${ }^{38-40}$

The strength of this study resides in our ability to longitudinally track the influence of a basket of contextual indicators and demonstrate how these predict success at medical school. For example, against the backdrop of noticeable sociodemographic differences within the sample, the results showed that, after adjusting for the effect of other variables, factors such as coming from neighbourhoods of low participation in higher education (POLAR 2 and 3), receiving free school meals or income support or not having university-educated parent were not significant independent predictors of performance at medical school. Much as the use of POLAR marker is considered problematic, ${ }^{41}$ especially among mature students, who are more likely to live in deprived areas than their school-leaver peers, ${ }^{42} 43$ our finding still resonates with other studies that demonstrate that the attainment gap between students from high-income and low-income areas disappears once students' prior achievement (as measured by UCAS Tariff) is accounted for in the analysis. $^{44}$

We also found that female gender, White ethnicity and being 21 or over on entry to medical school (the last of these in 2012 only; see later for further discussion) were independently related to high performance. Some of these findings resonate with prior research and indicate our sample was representative. For example, a great deal of research has concluded that females outperform males in academic and clinical assessments at medical school. ${ }^{20} 2145$ Equally, it has been reported that, at least within the UK medical school setting, students from ethnic minorities perform less well academically than 
the majority of the white students ${ }^{46}$ and that mature students outperform younger peers in certain aspects of assessment. ${ }^{22} 37 \mathrm{~A}$ follow-up research in the Foundation Programme years would be of interest to illuminate the extent of this pattern.

Although our data do not allow us to examine why students from state-funded schools significantly outperform students from independent schools, it is possible that once given equal access to resources, state-educated students take advantage of the opportunities available to them. Non-academic attributes such as motivation and resilience, known to be associated with positive academic and work-related outcomes for young people, ${ }^{47}$ may have helped them achieve at school and set them up to manage medical school effectively. There is a need for further research to explore the relationship between such non-cognitive attributes and performance at medical school and beyond.

In summary, the result of our analysis indicates that certain sociodemographic characteristics such as school have a small but significant influence on the outcome measures of interest. The models presented here have limited explanatory power of only $18 \%-22 \%$ of the variation in EPM ranking, which suggests the interaction of other factors not included in our models (see above). However, the fact that type of school (state-funded or privately funded) makes a significant contribution to the prediction of performance on the EPM compares interestingly to the figure of $23 \%$ for the predictive validity of school leaving examinations often cited in medical education. $^{21}$

The present study has various limitations that must be taken into consideration when interpreting findings. First, we included only students who were successfully admitted and completed their medical degree. Students who failed or dropped out were excluded from our analysis. While this may restrict the extent to which findings are representative of all medical students, note that the dropout and failure rates from medical school are very low. ${ }^{7849}$ A summary of sociodemographic characteristics and previous academic achievement support the observation that our sample represents the national medical student population; for example, the majority of the sample were from the highest socioeconomic class. ${ }^{22} 50$ The measures of disadvantage available to us (eg, NSSEC) are known to have weaknesses, ${ }^{41}$ but by including each of these separately in the analysis, we have provided more scrutiny of their utility. Other authors have adjusted for previous educational performance. ${ }^{22} 51$ We chose not to because school qualifications and their conversions to UCAS points are not comparable across the four countries within the UK. Although our management of EPM scores differs from the previous research using this outcome measure ${ }^{52}$ our method of differentiating the top achievers from the bottom achievers has been reported elsewhere as being suitable for exploratory research such as this. ${ }^{3753}$ There were differences between the two cohorts. Most notably there were proportionally many more graduates and mature students in the 2012 cohort. Obviously, there is a big overlap between these categories, but it is worth giving some context here to explain the differences between cohorts. Our dataset contains those who entered medical school in 2007 or 2008 and graduated in 2012 or 2013. This is quite a narrow window given, for example, about one-third of medical students (usually those entering as school leavers) may take a year out of programme to do a research degree (intercalate). Students may also extend their time at medical school due to weak performance and having to repeat a year. The 2012 data are, because of this narrow window, graduate heavy compared with the 2013 data. The 2013 data include more students and are perhaps more representative of a 'normal' graduating cohort as they include those that entered standard programmes in 2007 and 2008 graduate entry programmes in 2007/8/9. This may be why we found that, in 2012, mature students, who are mostly graduates, were more likely to finish in the highest EPM ranking than was the case in 2013. This emphasises the importance of replicating this study with other cohorts to see if the patterns we have identified are consistent over time. Furthermore, the localised adjustment of some of the cognitive competencies has implications for more sophisticated statistical models and this may influence the generalisability of the results. For example, it was not possible to extrapolate the average point score per A-level student because A levels are (mostly) restricted to English schools. As noted earlier, the EPM is directly measured by the individual medical schools, although we tried to minimise this variability by focusing on the extreme groups and deploying a mixed-effects logistic regression technique, there is no agreed approach for doing so. Future research should be less reliant on these local measures and instead focus on more national performance metrics like the Royal College postgraduate examinations or the proposed UK Medical Licensing Assessment (http://www.gmc-uk.org/ education/29000.asp).

This study has implications for future research and practice. Around $80 \%$ of applications to medical school come from independent and selective schools, ${ }^{54}$ yet medical students from state schools do better than those from independent schools. Is this because those who have attained the necessary qualifications for entry to medical school 'against the odds' are more self-directed or resilient? Other recent research hints that this might be the case, ${ }^{55}$ but further exploration is necessary. In relation to the wider discussion about the use of contextual markers in medical school admissions, it may be that there is an argument to accept lower scoring (UCAS tariff) applicants from state schools on the basis that they are likely to make up this discrepancy in performance. Certainly, there is an argument for encouraging high-achieving students from state schools into medicine. However, how to attract applicants from non-traditional backgrounds into medicine remains a challenge ${ }^{56}$ which is beyond the reach of this study to address. 
In conclusion, our findings suggest that medical students from state-funded schools do better at medical school than their counterparts from independent schools and prior attainment should be interpreted within the context of an individual's educational circumstances. Furthermore, we cannot ignore the influence of ethnicity, gender, age and the differences in medical programmes. We suggest the need for longer-term validity studies to provide insight into the outcomes of students, in particular, those from non-traditional backgrounds, as they progress through postgraduate years and go into practice.

Acknowledgements We thank UKMED for releasing the data for this project via a competitive bid process. We are grateful to the following for their support of the application to UKMED for this and other research projects: Dr Sally Curtis (University of Southampton, UK), Dr Sandra Nicholson (Barts and The London School of Medicine and Dentistry, UK), Professor Peter Johnston (NHS Education for Scotland, UK) and Dr Rhoda MacKenzie (University of Aberdeen, UK). We thank Daniel Smith and Andy Knapton of the General Medical Council of the UK for their support for the application and throughout the project, particularly regarding data linkage and troubleshooting. We thank Dr Gordon Prescott (University of Aberdeen, UK) for the statistical support.

Contributors JAC led the funding bid which was co-written by AJL and reviewed by KW and BK. KW and JAC advised on the nature of the data. BK managed the data and carried out the data analysis under the supervision of the other authors. AJL advised on all the statistical analysis. JAC guided the first draft of the introduction and discussion sections of this paper. BK and AJL wrote the first drafts of the methods and results sections. JC edited the drafts. All authors reviewed and agreed on the final draft of the paper.

Funding This study is part of Ben Kumwenda's doctoral programme of research funded by the UKCAT Research Panel, of which JC and RG are members.

Competing interests KW is the Special Advisor (Recruitment) for the UK's Foundation Programme (UKFPO).

Patient consent Obtained.

Provenance and peer review Not commissioned; externally peer reviewed.

Data sharing statement № additional data available as datasets held in safe haven.

Open Access This is an Open Access article distributed in accordance with the Creative Commons Attribution Non Commercial (CC BY-NC 4.0) license, which permits others to distribute, remix, adapt, build upon this work non-commercially, and license their derivative works on different terms, provided the original work is properly cited and the use is non-commercial. See: http://creativecommons.org/ licenses/by-nc/4.0/

(C) Article author(s) (or their employer(s) unless otherwise stated in the text of the article) 2017. All rights reserved. No commercial use is permitted unless otherwise expressly granted.

\section{REFERENCES}

1. McManus IC. Factors affecting likelihood of applicants being offered a place in medical schools in the United Kingdom in 1996 and 1997: retrospective study. BMJ 1998;317:1111-6.

2. Seyan K, Greenhalgh T, Dorling D. The standardised admission ratio for measuring widening participation in medical schools: analysis of UK medical school admissions by ethnicity, socioeconomic status, and sex. BMJ 2004;328:1545-6.

3. McManus IC, Woolf K, Dacre J, et al. The Academic Backbone: longitudinal continuities in educational achievement from secondary school and medical school to MRCP(UK) and the specialist register in UK medical students and doctors. BMC Med 2013;11:27.

4. Bourdieu P. The forms of capital. Richardson J, ed. handbook of Theory and Research for the Sociology of Education.. New York: Greenwood, 1986:241-58

5. Ball S. Class strategies and the educational market: the middle classes and social advantage. London: Routladge Falmer, 2003.

6. Archer L, Identities LC. inequalities and higher education. In: Archer L, Hutchings M, Ross A, eds. Higher education and Social Class: issues of exclusion and inclusions. London: routledge Falmer, 2003:175-91.

7. Scott I, Yeld N, McMillan J, ; et a/Equity and excellence in higher education: the case of the University of Cape Town. In: Bowen W, Kurzweil M, Tobin E, Pichler S, ; eds. Equity and excellence in American higher education. Charlottesville: university of Virginia Press, 2005:261-84.

8. Garlick PB, Brown G. Widening participation in medicine. BMJ 2008;336:1111-3.

9. Young ME, Razack S, Hanson MD, et al. Calling for a broader conceptualization of diversity: surface and deep diversity in four canadian medical schools. Acad Med 2012;87:1501-10.

10. Haroon C, Claire C, Lorraine D, et al. Vignoles Anna widening participation in higher education: analysis using linked administrative data. Journal of the Royal Statistical Society 2013;176:431-57.

11. Southgate E, Kelly BJ, Symonds IM. Disadvantage and the 'capacity to aspire' to medical school. Med Educ 2015;49:73-83.

12. British Medical Association. Equality and diversification in UK Medical Schools. London: BMA, 2009.

13. Gorard S. Who is missing from higher education? Cambridge Journal of Education 2008;38:421-37.

14. Peers IS, Johnston M. Influence of learning context on the relationship between A-level attainment and final degree performance: a meta-analytic review. Br J Educ Psychol 1994;64:1-18.

15. Independent Reviewer on Social mobility and Child Poverty. Fair access to professional careers. London: Cabinet Office, 2012 https://www.gov. uk/government/publications/fair-access-to-professional-careers-aprogress-report. [accessed in Nov 2016].

16. Gorard S, Smith $\mathrm{E}$, May H, et al. Review of widening participation research: addressing the barriers to participation in higher education. A report to HEFCE by the University of York, higher Education Academy and Institute for access studies. University of York 2006.

17. Palardy GJ. Differential school effects among low, middle, and high social class composition schools: a multiple group, multilevel latent growth curve analysis. School Effectiveness and School Improvement 2008;19:21-49.

18. Ndaji F, Little J, Coe R. A comparison of Academic Achievement in Independent and State Schools. Durham University: Centre for Evaluation and Monitoring, Durham University, 2016.

19. Lumb AB, Vail A. Comparison of academic, application form and social factors in predicting early performance on the medical course. Med Educ 2004;38:1002-5.

20. McManus IC, Woolf K, Dacre J. The educational background and qualifications of UK medical students from ethnic minorities. BMC Med Educ 2008;8:23.

21. Ferguson E, James D, Madeley L. Factors associated with success in medical school: systematic review of the literature. BMJ 2002;324:952-7.

22. McManus IC, Dewberry C, Nicholson S, et al. The UKCAT-12 study: educational attainment, aptitude test performance, demographic and socio-economic contextual factors as predictors of first year outcome in a cross-sectional collaborative study of 12 UK medical schools. BMC Med 2013;11:244.

23. Thiele T, Pope D, Singleton A, et al. Role of students' context in predicting academic performance at a medical school: a retrospective cohort study. BMJ Open 2016;6:11:e010169.

24. Higher Education Funding Council for England. schooling effects on higher education achievement. Bristol: HEFCE, 2003.

25. Higher Education Funding Council for England. differences in degree outcomes: key findings. Bristol: HEFCE, 2014.

26. Cleland J, Dowell J, McLachlan J, et al; Identifying best practice in the selection of medical students: GMC Res Report, 2012.

27. Medical Schools Council. Selecting for excellence - Final Report. London: Medical Schools Council, 2014.

28. Williamson H. The Milltown Boys revisited. London: Berg, 2004.

29. Cleland J, Nicholson S, Patterson F, et al; The use of contextual data in medical school selection processes: a mixed-method programme of research. (unpublished, 2016.

30. Cleland J, Dowell J, McLachlan J, et al; Identifying best practice in the selection of medical students: a project commissioned by the General Medical Council, 2012.

31. Mathers J, Sitch A, Marsh JL, et al. Widening access to medical education for under-represented socioeconomic groups: population based cross sectional analysis of UK data, 2002-6. BMJ 2011;342:d918.

32. Higher Education Funding Council for England. Widening participation and fair access research strategy consultation document. Bristol, 2004.

33. Higher Education Funding Council for England. Young participation in higher education. Research report. Bristol, 2015. 
34. Lievens F, Patterson F, Corstjens J, et al. Widening access in selection using situational judgement tests: evidence from the UKCAT. Med Educ 2016;50:624-36.

35. Petty-Saphon K, Walker KA, Patterson F, et al. Situational judgment tests reliably measure professional attributes important for clinical practice. Adv Med Educ Pract 2017;8:21-3.

36. Preacher KJ, Rucker DD, MacCallum RC, et al. Use of the extreme groups approach: a critical reexamination and new recommendations. Psychol Methods 2005;10:178-92.

37. Adam J, Bore M, Childs R, et al. Predictors of professional behaviour and academic outcomes in a UK medical school: a longitudinal cohort study. Med Teach 2015;37:868-80.

38. Smith J, Naylor R. Schooling effects on subsequent university performance: evidence for the UK university population. Econ Educ Rev 2005;24:549-62.

39. Hoare A, Johnston R. Widening participation through admissions policy - a British case study of school and university performance. Studies in Higher Education 2011;36:21-41.

40. Crawford C. Socio-economic differences in university outcomes in the UK: drop-out, degree completion and degree class. 14: Institute for Fiscal Studies Working Paper W, 2014.

41. Boliver V, Gorard S, Siddiqui N. Will the use of Contextual Indicators Make UK Higher Education Admissions Fairer? Education Sciences 2015;5:306-22.

42. Do PC, Parry J, Mathers J, et al. Monitoring the widening participation initiative for access to medical school: are present measures sufficient? Med Educ 2006;40:750-8.

43. James D, Ferguson E, Powis D, et al. Graduate entry to medicine: widening academic and socio-demographic access. Med Educ 2008;42:294-300.

44. Nattavudh P, Anna V. The socio-economic gap in university drop out: University of York, 2009.

45. Svirko E, Lambert T, Goldacre MJ, Gender GMJ. Gender, ethnicity and graduate status, and junior doctors' self-reported preparedness for clinical practice: national questionnaire surveys. J $R$ Soc Med 2014;107:66-74.
46. Woolf K, Potts HW, McManus IC. Ethnicity and academic performance in UK trained doctors and medical students: systematic review and meta-analysis. BMJ 2011;342:d901.

47. Gutman LM, Schoon I. The impact of non-cognitive skills on outcomes for young people. Education Endowment Foundation. $2013 \mathrm{http}: / /$ educationendowmentfoundation org uk/uploads/pdf/ Non-cognitive_skills_literature_review pdf.

48. Office NA. Staying the course: The retention of students in higher education. Report by the Comptroller and Auditor General. London: The Stationary Office, 2007.

49. MacCulloch A. Learning from Futuretrack: Dropout from higher education - BIS RESEARCH PAPER NO. 168. Department for Business Innovation and skills. London, 2014.

50. James D, Yates J, Nicholson S. Comparison of A level and UKCAT performance in students applying to UK medical and dental schools in 2006: cohort study. BMJ 2010;340:c478.

51. Tiffin PA, Dowell JS, McLachlan JC. Widening access to UK medical education for under-represented socioeconomic groups: modelling the impact of the UKCAT in the 2009 cohort. BMJ: British Medical Journal 2012:344.

52. MacKenzie RK, Cleland JA, Ayansina D, et al. Does the UKCAT predict performance on exit from medical school? A national cohort study. BMJ Open 2016;6:6.

53. Cousans F, Patterson F, Edwards $\mathrm{H}$, et al. Evaluating the complementary roles of an SJT and academic assessment for entry into clinical practice. Adv Health Sci Educ Spec 2016.

54. Garrud P. Help and hindrance in widening participation: commissioned research report. Medical schools council-selecting for excellence: University of Nottingham, 2014.

55. Nicholson S, Cleland JA. "It's making contacts": notions of social capital and implications for widening access to medical education. Adv Health Sci Educ Theory Pract 2017;22:1-14.

56. Steven K, Dowell J, Jackson C, et al. Fair access to medicine? retrospective analysis of UK medical schools application data 20092012 using three measures of socioeconomic status. BMC Med Educ 2016;16:10. 
Correction: The relationship between school type and academic performance at medical school: a national, multicohort study

Kumwenda B, Cleland JA, Walker K, et al. The relationship between school type and academic performance at medical school: a national, multi-cohort study. BMJ Open 2017;7:e016291. doi: 10.1136/bmjopen-2017-016291

The paper should have the following Acknowledgements section:

Acknowledgements Data Source: - UK Medical Education Database ("UKMED") UKMEDP26 extract generated on 12/08/2016. Approved for publication on $27 / 03 / 2017$. We are grateful to UKMED for the use of these data. However, UKMED bears no responsibility for their analysis or interpretation. The data includes information derived from that collected by the Higher Education Statistics Agency Limited ("HESA") and provided to the GMC ("HESA Data"). Source: HESA Student Record 2007/2008 and 2008/2009 Copyright Higher Education Statistics Agency Limited. The Higher Education Statistics Agency Limited makes no warranty as to the accuracy of the HESA Data, cannot accept responsibility for any inferences or conclusions derived by third parties from data or other information supplied by it.

Open Access This is an Open Access article distributed in accordance with the Creative Commons Attribution Non Commercial (CC BY-NC 4.0) license, which permits others to distribute, remix, adapt, build upon this work non-commercially, and license their derivative works on different terms, provided the original work is properly cited and the use is non-commercial. See:http://creativecommons.org/licenses/by-nc/4.0/

(c) Article author(s) (or their employer(s) unless otherwise stated in the text of the article) 2017. All rights reserved. No commercial use is permitted unless otherwise expressly granted.

BMJ Open 2017;8:e016291corr1. doi:10.1136/bmjopen-2017-016291corr1

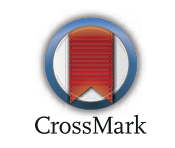

